\title{
Full implementation of the WHO Framework Convention on Tobacco Control in the Eastern Mediterranean Region is the responsibility of all
}

Ahmed Al-Mandhari, ${ }^{1}$ Asmus Hammerich, ${ }^{2}$ Fatimah El-Awa, ${ }^{3}$ Douglas Bettcher ${ }^{4}$ and Ahmed Mandil 5

${ }^{1}$ Regional Director, World Health Organization Regional Office for the Eastern Mediterranean, Cairo, Egypt. ${ }^{2}$ Director, Department of Noncommunicable Diseases and Mental Health, World Health Organization Regional Office for the Eastern Mediterranean, Cairo, Egypt. ${ }^{3}$ Regional Advisor, Tobacco Free Initiative, World Health Organization Regional Office for the Eastern Mediterranean, Cairo, Egypt. ${ }^{4}$ Office of the Director-General, World Health Organization, Geneva, Switzerland. ${ }^{5}$ Coordinator, Research, Development and Innovation, World Health Organization Regional Office for the Eastern Mediterranean, Cairo, Egypt. (Correspondence to: Fatimah El-Awa: elawaf@who.int).

Citation: Al-Mandhari A; Hammerich A; El-Awa F; Bettcher D; Mandil A. Full implementation of the WHO Framework Convention on Tobacco Control in the Eastern Mediterranean Region is the responsibility of all. East Mediterr Health J. 2020;26(1):4-5. https://doi.org/10.26719/2020.26.1.4

Copyright (C) World Health Organization (WHO) 2020. Open Access. Some rights reserved. This work is available under the CC BY-NC-SA 3.0 IGO license (https://creativecommons.org/licenses/by-nc-sa/3.o/igo).

Although the World Health Organization Framework Convention on Tobacco Control (FCTC) came into force in 2005, the tobacco control challenge continues to escalate. Despite the fact that tobacco use is finally projected to decrease in the Eastern Mediterranean Region (EMR), as indicated in the WHO Global Report on Trends in the Prevalence of Tobacco Use (1), the tobacco epidemic is still far from over.

The challenges facing the Region do not have a single source; the tobacco epidemic started as a multi-faceted problem and remains so today. The emergency situation in several EMR countries is pushing tobacco control down the list of priorities for decision-makers, whether directly or indirectly affected by regional conflict. The existence of unregulated and novel tobacco products, such as e-cigarettes, in many EMR countries complicates the situation further. Such products allow affordable access to tobacco products for young people, which consequently increases nicotine dependence and thus worsens the tobacco epidemic (2).

The apparent hesitation demonstrated by some Member States in taking action to implement WHO FCTC measures continues to be a significant issue. This is often due to worries regarding trade agreements and the threat of litigation, following case examples witnessed in Australia, Uruguay and other countries (3-5). Moreover, the influence of the tobacco industry and its continued interference in tobacco control policy-making remains a complicating factor (6).

As a consequence of this situation, the prevalence of young people using tobacco products is increasing in many countries, reaching as high as $40 \%$ among males aged 13-15 years in a number of countries in the Region. Furthermore, while in the past there was a generally low prevalence of females using tobacco products compared to males, a sharp increase in the prevalence of tobacco use among young females is being witnessed, especially in the use of waterpipe and smokeless tobacco (7).

Despite the many challenges in the Region, commitment to improving tobacco control measures does exist. Member States are confident of the value of reducing tobacco use, as is evident in the work led by ministries of health in coordination and collaboration with key partners, including legislators and parliamentarians. In 2018, during the 65th Session of the WHO Regional Committee for the Eastern Mediterranean, Member States adopted both the Regional Strategy and Action Plan for Tobacco Control (8) in addition to the Regional Framework for Tobacco Control (9) ${ }^{1}$. Results from the 2019 WHO Report on the Global Tobacco Epidemic indicate that about $70 \%$ of people in the Region are covered by at least two MPOWER measures at the highest level of achievement $(10)^{2}$. Still, only $25 \%$ of people in the Region are covered by four MPOWER measures at the highest level (10). Efforts should not be limited to increasing political commitment among governments but should extend to stronger national action at the technical and policy fronts.

Full implementation of the WHO FCTC is needed to end the tobacco epidemic (11-13). Despite many countries globally having already achieved significant reductions in the prevalence of tobacco use (14), research shows that fully implementing the measures of the WHO FCTC and the MPOWER package could further reduce prevalence in countries of the Region by as much as $40 \%$ in 5 years (15).

This is an achievable goal, but cannot be attained by the efforts of one party alone. It requires collaboration by Member States, United Nations agencies, nongovernmental organizations, donors and other

\footnotetext{
This Framework is included in this special supplement of the EMHJ.

The WHO MPOWER package was introduced in 2008 as a tool to help countries implement demand-reduction measures of the WHO FCTC. It consists of the following six measures, of which the latter five are direct demand-reduction measures: Monitor tobacco use and prevention policies, Protect people from tobacco smoke, Offer help to quit tobacco use, Warn about the dangers of tobacco, Enforce comprehensive bans on tobacco advertising, promotion and sponsorship, and Raise taxes on tobacco. The coverage figures given here include just the direct demand-reduction measures (i.e. do not include the monitoring component).
} 
stakeholders, who together stand firm in recognizing tobacco control as a public health priority. It is only through such prioritization and collaboration that by the next WHO FCTC anniversary one could expect to reach the WHO noncommunicable diseases voluntary target of a $30 \%$ reduction in tobacco use by 2025 (16). The Vision
2023 for the Eastern Mediterranean Region provides a concrete platform for collaboration and the reinforcement of strong partnerships with all stakeholders (17), underlining the fact that tobacco control is a fight in which every assistance counts and every action matters.

\section{References}

1. World Health Organization. WHO global report on trends in the prevalence of tobacco use 2000-2025 (3rd edition). Geneva: World Health Organization; 2019.

2. World Health Organization. Global Youth Tobacco Survey 2014-2017. Geneva: World Health Organization; 2018.

3. World Health Organization. WTO Panel rejects claims concerning tobacco plain packaging in Australia. Geneva: World Health Organization; 2018 (https://www.who.int/tobacco/wto-panel-rejects-claims-tobacco-plain-packaging-australia/en/, accessed 1211 2019).

4. World Health Organization. International tribunal orders tobacco company to pay Australia's costs of the arbitration over tobacco plain packaging. Geneva: World Health Organization; 2017 (https://www.who.int/tobacco/communications/highlights/international-tribunal-plain-packaging/en/, accessed 12 November 2019).

5. Tobacco Free Kids. Uruguay defeats Philip Morris challenge to its strong tobacco control laws. Washington DC: Tobacco Free Kids; 2016 (https://www.tobaccofreekids.org/press-releases/2016_07_08_uruguay, accessed 12 November 2019).

6. World Health Organization Regional Office for the Eastern Mediterranean (WHO/EMRO). Technical package: stop the tobacco industry. Cairo: WHO/EMRO; 2019.

7. World Health Organization. Global Youth Tobacco Survey 2010-2017. Geneva: World Health Organization; 2018.

8. World Health Organization Regional Office for the Eastern Mediterranean (WHO/EMRO). Regional strategy and action plan for tobacco control reflecting the commitments of the WHO Framework Convention on Tobacco Control. Cairo: WHO/EMRO; 2018.

9. World Health Organization Regional Office for the Eastern Mediterranean (WHO/EMRO). Regional Framework for Action on Tobacco Control. Cairo: WHO/EMRO; 2018.

10. World Health Organization. WHO report on the global tobacco epidemic. Geneva: World Health Organization; 2019:152-153.

11. Mackay JM, Bettcher DW, Minhas R, Schotte K. Successes and new emerging challenges in tobacco control: addressing the vector. Tob Control. 2012;21:77-79.

12. Thomson G, Edwards R, Wilson N, Blakely T. What are the elements of the tobacco endgame? Tob Control. 2012;21:293-295.

13. Puska P, Daube M, WHO FCTC Impact Assessment Expert Group. Impact assessment of the WHO Framework Convention on Tobacco Control: introduction, general findings and discussion. Tob Control. 2019;28:S2.

14. Gravely S, Giovino GA, Craig L, Commar A, D'Espaignet ET, Schotte K, et al. Implementation of key demand-reduction measures of the WHO Framework Convention on Tobacco Control and change in smoking prevalence in 126 countries: an association study. Lancet Public Health. 2017;2:e166-74.

15. World Health Organization Regional Office for the Eastern Mediterranean (WHO/EMRO). Effects of meeting MPOWER requirements on smoking rates and smoking-attributable deaths for the Member States and Territories of the Eastern Mediterranean Region. Cairo: WHO/EMRO; 2018 (http://www.emro.who.int/tfi/publications/mpower-measures-to-reduce-tobacco-use.html, accessed 13 November 2019).

16. World Health Organization. WHO Global Action Plan for the Prevention and Control of Noncommunicable Diseases $2013-2020$. Geneva: World Health Organization; 2013.

17. World Health Organization Regional Office for the Eastern Mediterranean (WHO/EMRO). Vision 2023 Eastern Mediterranean Region: Health for All by All. Cairo: WHO/EMRO; 2018 (https://apps.who.int/iris/bitstream/handle/10665/326911/RD_Vision_2018_20675_en.pdf?sequence=1\&isAllowed=y). 